finding is not surprising since elastin is distributed in large measure beyond the alveoli to bronchial and vascular structures. The increased levels of desmosine in the non-emphysematous phenotype indicate that this marker may be useful for detecting tissue degradation in the non-emphysematous COPD phenotype. The improved technical ability to measure desmosine in sputum and plasma, as well as in urine, significantly increases its usefulness as a marker of lung matrix degradation and should be more widely applied in COPD.

\section{IMPLICATIONS OF THE STUDY}

Overall, this study presents several significant insights to delineate phenotypes within the broad category of COPD:

- CT scanning is essential for identifying COPD patients with and without a significant component of pulmonary emphysema.

- Induced sputum can yield characterising markers for various COPD phenotypes which may vary from the findings in BAL fluid. Where possible, studies should compare findings in sputum with those from BAL fluid in the same patients.

- While the patients in this study had moderate to severe COPD, studies in patients with mild or early COPD would be worthwhile to determine whether the same enzymatic and inflammatory mediators are detected in early disease.

- The source of increased levels of MMP-9 with respect to neutrophil versus macrophage should be better defined to identify possible therapeutic targets.

- The increase in eosinophils in induced sputum in the emphysema phenotype deserves study in larger series of patients to determine its consistency. Also, the significance of eosinophilia immunologically, functionally and pathologically needs to be better understood in COPD, especially in the emphysema phenotype.

The findings in this study indicate how much more we still need to learn about the cellular and cytokine reactions of specific phenotypes in COPD, and how they differ from the asthmatic state. $^{21}$

Thorax 2006;61:1031-1032.

doi: $10.1136 /$ thx.2006.066308

Correspondence to: $\operatorname{Dr} G M$ Turino, Department of Medicine, St Luke's-Roosevelt Hospital Center, 1000 Tenth Avenue, New York, NY10019, USA; gmt1@columbia.edu

Competing interests: none declared.

\section{REFERENCES}

1 Pauwels RA, Buist AS, Calverley PM, et al. Global strategy for diagnosis, management and prevention of chronic obstructive pulmonary disease: NHLBI/WHO Global Initiative for Chronic Obstructive Lung Disease (GOLD) Workshop Summary. Am J Respir Crit Care Med 2001;163:1256-76.

2 Cello BR, MacNee W. Standards for the diagnosis and treatment of patients with COPD: a summary of the ATS/ERS position paper. Eur Respir J 2004;23:932-46.

3 Boschetto P, Quintavalle S, Zeni E, et al. Association between markers of emphysema and more severe chronic obstructive pulmonary disease. Thorax 2006:61:1037-42.

4 Celli BR, Cote CG, Marin JM, et al. The body-mass index, airflow obstruction, dyspnea and exercise capacity index in chronic obstructive pulmonary disease. N Engl J Med 2004;350:1005-12.

5 Boschetto P, Miniati M, Miotto D, et al. Emphysema phenotype in chronic obstructive pulmonary disease patients. Eur Respir $J$ 2003;21:450-4.

6 Finlay GA, Russell KJ, McMahon KJ, et al Elevated levels of matrix metalloproteinases in bronchoalveolar lavage fluid of emphysematous patients. Thorax 1997;52:502-6.
7 Finlay GA, O'Driscoll LR, Russell KJ, et al. Matrix metalloproteinase expression and production by alveolar macrophages in emphysema. Am J Respir Crit Care Med 1997;156:240-7.

8 Bousquet J, Chanez P, Lacoste JY, et al. Eosinophilic inflammation in asthma. NEngl J Med 1990;323:1033-9.

9 Holgate ST. Reflection by the Chairman. Am Rev Respir Dis 1991;143:1175-6.

10 Barnes PJ, Chowdhury B, Kharitonov SA, et al Pulmonary biomarkers in chronic obstructive pulmonary disease. Am J Respir Crit Care Med 2006;174:6-14.

11 Saetta M, DiStefano A, Maestrelli P, et al. Airway eosinophilia in chronic bronchitis during exacerbations. Am J Respir Crit Care Med 1994; 150:1646-52.

12 Fujimoto K, Yasou M, Urushibata K, et al. Airway inflammation during stable and acutely exacerbated chronic obstructive pulmonary disease. Eur Respir J 2005;25:640-6.

13 Louis RE, Cataldo D, Buckley MG, et al. Evidence of mast-cell activation in a subset of patients with eosinophilic chronic obstructive pulmonary disease. Eur Respir 2002;20:325-31.

14 Brightling CE, Monteiro W, Ward R, et al. Sputum eosinophilia and short-term response to prednisolone in chronic obstructive pulmonary disease: a randomized controlled trial. Lancet 2000;356: 1480

15 Brightling CE, McKenna S, Hargadon B, et al. Sputum eosinophilia and the short term response to inhaled mometasone in chronic obstructive pulmonary disease. Thorax 2005;60:193-8.

16 Saetta M, Turato G, Maestrelli $P$, et al. Cellular and structural bases of chronic obstructive pulmonary disease. Am J Respir Crit Care Med 2001;163:1304-9.

17 Barnes PJ, Shapiro SD, Pauwels RA. Chronic obstructive pulmonary disease: molecular and cellular mechanisms. Eur Respir J 2003;22:672-88

18 O'Connor CM, FitzGerald MX. Matrix metalloproteases and lung disease. Thorax 1994:49:101-8.

19 Shapiro SD. Proteinases in chronic obstructive pulmonary disease. Biochem Soc Trans 2002;30:98-102.

20 Sires UI, Murphy G, Baragi VM, et al. Matrilysin is much more efficient than other matrix metalloproteinases in the proteolytic inactivation of alpha 1-antitrypsin. Biochem Biophys Res Commun 1994;204:613-20.

21 Fabbri LM, Romagnoli M, Corbetta L, et al. Differences in airway inflammation in patients with fixed airflow obstruction due to asthma or chronic obstructive pulmonary disease. Am J Respir Crit Care Med 2003;167:418-24.

\title{
Underdiagnosed chronic obstructive pulmonary disease in England: new country, same story
}

\section{M Mannino}

\section{Underdiagnosis or misdiagnosis of COPD is a problem in England too}

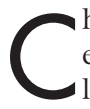
onic obstructive pulmonary disease (COPD) remains one of the emerging as increasingly important in the developing world. Despite its importance, COPD is not well recognised by the general public and frequently goes undiagnosed in people who have evidence of it. This underdiagnosis of people with evidence of obstruction on spirometry (generally adults with an $\mathrm{FEV}_{1} / \mathrm{FVC}$ ratio $<70 \%$ ) has been previously documented in the United States ${ }^{1}$ and Korea. ${ }^{2}$

The paper by Shahab and colleagues in this issue of Thorax shows that underdiagnosis and, in all likelihood, misdiagnosis, is a factor in England also. ${ }^{3}$ Their key finding was that $13.3 \%$ of the population aged 35 and older had evidence of COPD that would, in general, correspond to GOLD stage 1 or more severe disease. ${ }^{4}$ Bronchodilator response was not evaluated, so this would not meet strict GOLD criteria and, if this population is similar to the Norwegian adult population, ${ }^{5}$ one might expect the "post-bronchodilator" prevalence of COPD to be 20-25\% lower. 
Whether this shifting classification is important either clinically or epidemiologically is unclear. While some research has suggested that bronchodilator responsiveness may help to distinguish asthma and COPD or improve the prediction of outcomes, ${ }^{67}$ pre-bronchodilator classification of lung function using GOLD criteria has been shown to predict mortality and other adverse outcomes in several different populations. ${ }^{8-10}$

A second important finding was that, among survey participants with evidence of COPD, only $18.8 \%$ had a current diagnosis of any lung disease. ${ }^{3}$ When looking at participants in the most severe category, correlating to GOLD stage 3 or more severe disease, only $46.8 \%$ had a diagnosis of lung disease and, of those with a diagnosis, that diagnosis was asthma in 47 of 74 $(63.5 \%)$. The degree of underdiagnosis of disease in this population is very similar to that previously reported in the United States. ${ }^{11}$ In the absence of a diagnosis, effective interventions are unlikely to occur. The question of a misdiagnosis by diagnosing COPD as asthma is complex. COPD and asthma, generally thought to represent different pathophysiological processes, share some important similarities in the adult population with regard to disease presentation and treatment, ${ }^{12}$ and there may be overlap between COPD and asthma in a significant proportion of the population. ${ }^{1}$ The question of whether treating COPD like asthmawith inhaled corticosteroids or leukotriene antagonists-provides benefits with regard to morbidity and mortality is central to several recently completed and ongoing investigations..$^{13-15}$

A third important finding in this study is the relation between current smoking and COPD. The authors reported that $34.9 \%$ of the population with COPD were current smokers compared with $22.4 \%$ of the population without COPD. ${ }^{3}$ They also reported that the prevalence of current smoking increased as COPD severity increased, from $29.5 \%$ in the mildest category to $40.5 \%$ in the most severe category. The link between cigarette smoking and COPD is well established and undeniable. ${ }^{16-18}$ Similarly, smoking cessation is the most important intervention in COPD, with demonstrated effects on both morbidity and mortality. ${ }^{19}$ The authors suggest that smokers with COPD were more "cigarette dependent" than smokers without COPD. ${ }^{3}$ The 382 smokers with COPD did, in fact, smoke significantly more cigarettes per day than the 1596 smokers without COPD (16.3 $v$ 14.8), had higher cotinine levels (322 v $278 \mathrm{ng} / \mathrm{ml}$ ) and a higher Heavy
Smoking Index dependency rating (3.9v 3.6). When restricted to participants with COPD, however, there was no evidence of a dose-response relation for any of these measures as severity of COPD increased. In fact, among subjects in the highest severity category for COPD, both the cigarettes smoked per day and the dependency ratings were similar to those seen in smokers without COPD. Are smokers with COPD more cigarette dependent than smokers without COPD? While this remains a possibility, other explanations may be responsible for the results seen in this study. For example, the acute and subacute changes in lung function seen in active smokers may have been enough, in a population study, to classify "normal" subjects who are close to the $70 \%$ threshold as those with COPD. ${ }^{2021}$

Another aspect of the relation between smoking and COPD important in this study was the burden of disease among never and former smokers. Overall, 711 of $1093(65.1 \%)$ of those classified as having COPD were not current smokers. ${ }^{3}$ Among people with clinically relevant COPD corresponding to GOLD stage 2 or higher, 390 of 638 (61.1\%) were not current smokers. While some never or former smokers misclassified themselves (based on the cotinine levels), this finding points to the reality that COPD can develop and progress in people who have never smoked or in people who have stopped smoking. In this study, among ever smokers aged 65 and older, over 65\% had stopped smoking. In all likelihood these people will suffer from limitations, morbidity, and mortality related to COPD. What factors contribute to the development and progression of COPD in the never smoker? This analysis points to some non-smoking factors previously shown to be risks for COPD such as social class and working in manual labour (as a surrogate for a dusty occupation)..$^{22} 23$

In conclusion, this survey from England corroborates findings from other studies in other countries with different health delivery systems. ${ }^{12}$ It also presents some interesting paradoxes: (1) COPD is a common disease among the adult population yet remains a hidden disease that is frequently undiagnosed, even when causing severe impairment; (2) when diagnosis of a "disease" in people with airflow limitation does occur, it is frequently asthma which may represent a misdiagnosis; and (3) smoking cessation remains the most effective intervention, yet the majority of disease in this population could be found in former and never smokers. This study, as those in other countries, shows that objective measures of pulmonary function need to be a more routine part of the assessment of the adult patient.

Thorax 2006;61:1032-1034. doi: $10.1136 /$ thx.2006.067785

Correspondence to: Dr D M Mannino, Division of Pulmonary, Critical Care and Sleep Medicine, University of Kentucky Medical Center, 740 S Limestone, K-528, Lexington, KY 40536, USA; dmannino@uky.edu

$\operatorname{Dr}$ Mannino serves on advisory boards or speakers' bureaus for GlaxoSmithKline, Pfizer, Ortho-Biotech, Novartis, Astra-Zeneca, Dey, and Boehringer-Ingelheim.

\section{REFERENCES}

1 Mannino DM, Gagnon RC, Petty TL, et al. Obstructive lung disease and low lung function in adults in the United States: data from the National Health and Nutrition Examination Survey, 19881994. Arch Intern Med 2000;160:1683-9.

2 Kim DS, Kim YS, Chung KS, et al. Prevalence of chronic obstructive pulmonary disease in Korea: a population-based spirometry survey. Am J Respir Crit Care Med 2005; 172:842-7.

3 Shahab L, Jarvis MJ, Britton J, et al. Prevalence, diagnosis, and relation to tobacco dependence of chronic obstructive pulmonary disease in a nationally representative population sample. Thorax 2006:61:1043-7.

4 Pauwels RA, Buist AS, Calverley PM, et al. Global Strategy for the Diagnosis, Management, and Prevention of Chronic Obstructive Pulmonary Disease. NHLBI/WHO Global Initiative for Chronic Obstructive Lung Disease (GOLD) workshop summary. Am J Respir Crit Care Med 2001;163:1256-76.

5 Johannessen A, Omenaas ER, Bakke PS, et al. Implications of reversibility testing on prevalence and risk factors for chronic obstructive pulmonary disease: a community study. Thorax disease: a comm

6 Hansen EF, Phanareth K, Laursen LC, et al. Reversible and irreversible airflow obstruction as predictor of overall mortality in asthma and chronic obstructive pulmonary disease. Am J Respir Crit Care Med 1999; 159:1267-71.

7 Ulrik CS, Frederiksen J. Mortality and markers of risk of asthma death among 1,075 outpatients with asthma. Chest 1995; 108:10-5

8 Mannino DM, Buist AS, Petty TL, et al. Lung function and mortality in the United States: data from the First National Health and Nutrition Examination Survey follow up study. Thorax 2003;58:388-93.

9 Mannino DM, Doherty DE, Sonia BA. Global Initiative on Obstructive Lung Disease (GOLD) classification of lung disease and mortality: findings from the Atherosclerosis Risk in Communities (ARIC) study. Respir Med 2006;100:115-22.

10 Mannino DM, Davis KJ. Lung function decline and outcomes in an elderly population. Thorax 2006;61:472-7

11 Mannino DM, Gagnon RC, Petty TL, et al. Obstructive lung disease and low lung function in adults in the United States: data from the National Health and Nutrition Examination Survey, 19881994. Arch Intern Med 2000;160:1683-9.

12 Buist AS. Similarities and differences between asthma and chronic obstructive pulmonary disease: treatment and early outcomes. Eu Respir J Suppl 2003;39:30-5s.

13 Sin DD, Wu L, Anderson JA, et al. Inhaled corticosteroids and mortality in chronic obstructive pulmonary disease. Thorax 2005;60:992-7

14 Vestbo J. The TORCH (Towards a Revolution in COPD Health) survival study protocol. Eur Respir J 2004;24:206-10.

15 Celik P, Sakar A, Havlucu Y, et al. Short-term effects of montelukast in stable patients with 
moderate to severe COPD. Respir Med 2005:99:444-50.

16 Lundback B, Lindberg A, Lindstrom $M$, et al. No 15 but $50 \%$ of smokers develop COPD? Report from the Obstructive Lung Disease in Northern Sweden studies. Respir Med 2003:97:1 15-22.

17 US Department of Health and Human Services, Public Health Service, Centers for Disease Control, et al. Women and smoking: a report of the Surgeon General. Atlanta, GA: Department of Health and Human Services, 2001.

18 US Department of Health and Human Services, Public Health Service, Centers for Disease
Control, et al. The health consequences of smoking: a report of the Surgeon General. Atlanta, GA: Department of Health and Human Services, 2004.

19 US Department of Health and Human Services, Public Health Service, Centers for Disease Control, et al. Reducing tobacco use: a report of the Surgeon General. Atlanta, GA: Department of Health and Human Services, 2000.

20 Anthonisen NR, Connett JE, Kiley JP, et al. Effects of smoking intervention and the use of an inhaled anticholinergic bronchodilator on the rate of decline of $\mathrm{FEV}_{1}$ : the Lung Health Study. JAMA 1994;272:1497-505.
21 Willemse BW, PostmaDS, Timens W, etal. The impact of smoking cessation on respiratory symptoms, lung function, airway hyperresponsiveness and inflammation. Eur Respir J 2004;23:464-76.

22 Hnizdo E, Sullivan PA, Bang KM, et al. Association between chronic obstructive pulmonary disease and employment by industry and occupation in the US population: a study of data from the Third National Health and Nutrition Examination Survey. Am J Epidemiol 2002; 156:738-46

23 Trupin L, Earnest G, San Pedro M, et al. The occupational burden of chronic obstructive pulmonary disease. Eur Respir J 2003;22:462-9.

\section{Alpha-1-antitrypsin augmentation treatment: does one size fit all?}

\section{J Stolk}

\section{A new model for the individual pharmacokinetic assessment of patients requiring AAT augmentation therapy}

A lpha-1-antitrypsin (AAT) is synthesised and secreted in the liver by hepatocytes. Individuals who inherit homozygous $\mathrm{Z}$ alleles of AAT have a serum deficiency (AATD) resulting from accumulation of aberrant polymerised AAT in the endoplasmic reticulum of hepatocytes. ${ }^{1}$ The most specific therapeutic approach for AATD is augmentation therapy-that is, intravenous administration of purified AAT which aims to raise serum levels above the protective threshold of $0.5 \mathrm{~g} / \mathrm{l}$ $(\sim 11 \mu \mathrm{M})$ to protect against proteolytic destruction of alveoli and development of emphysema. ${ }^{2}$ Based on current understanding, and confirmed by the American Food and Drug Administration CBER Blood Products Advisory Committee in 1998, the risk of emphysema increases as the serum level of AAT falls below a socalled "protective" threshold of $11 \mu \mathrm{M}$. Of the approximately 100 different alleles for AAT variants, 10-15 are associated with serum levels below this threshold while the $\mathrm{Z}$ allele is by far the most common deficient variant, accounting for 95\% of the clinically recognised cases of severe AATD. ${ }^{4}$

The first study that applied infusions of pooled human plasma purified AAT at doses of $60 \mathrm{mg} / \mathrm{kg}$ once weekly showed that the serum levels could be restored to even above the protective level. ${ }^{5}$ Subsequent studies examined other doses and administration intervals and used different outcome measures and study designs. ${ }^{6}$ In those studies a high level of variability between subjects was seen in the trough serum level in response to dosing.
AAT augmentation treatment is now available in more than 10 countries around the world and the product is provided by an increasing number of pharmaceutical companies. Remarkably, the cost of this expensive treatment did not decline when more suppliers came on the market. This warrants an optimal dosing regimen for individual patients, an aspect that is addressed by Soy et al in this issue of Thorax. ${ }^{7}$ By applying population pharmacokinetic simulation, the authors showed that intervals between infusions of more than 1 week are possible in most patients while maintaining an appropriate threshold level of serum AAT. Soy and co-workers provide a model (in Appendix 2 of their paper) that can be easily used by physicians for tailoring a treatment regimen satisfying both the patient's desired frequency of infusions and the optimal trough level of AAT. Schedules with an interval longer than 1 week are more convenient for patients who can only receive their treatment in clinics rather than at home.

Piitulainen et al have previously shown that reduction of infusion frequency to every 3 days saves on the cost of the product while maintaining a more stable AAT plasma level. ${ }^{8}$ Their approach was proposed for self-treatment at home. Taken together, the data of Soy and Piitulainen suggest that every newly detected patient who fits the criteria for AAT augmentation treatment should have an individual pharmacokinetic assessment after the first infusion(s).

So far, only the biochemical efficacy of the augmentation treatment has been shown, while the effect on biomarkers relevant to the development of emphysema or clinical efficacy of AAT on pulmonary function and emphysema progression by controlled clinical trials is still unknown. To conduct studies that address these issues is difficult because of the rare occurrence of AATD and its inherent wide geographical spread of patients within a country. However, the model presented by Soy et al facilitates the design of such studies because the dosing regimen can now easily be tailored to a predefined trough level of AAT to investigate its effect on selected biomarkers. This may answer the question as to whether the $11 \mu \mathrm{M}$ trough level is a size that should fit all patients or whether more tailored dosing is a prerequisite for the detection of clinical benefit of this treatment.

Thorax 2006;61:1034.

doi: 10.1136/thx.2006.067710

Correspondence to: Dr J Stolk, Department of Pulmonology, Leiden University Medical Center, P O Box 9600, 2300 RC Leiden, The Netherlands; j.stolk.long@lumc.nl

Competing interests: none declared.

\section{REFERENCES}

1 Carrell RW, Lomas DA. Alpha-1-antitrypsin deficiency: a model for conformational diseases. N Engl J Med 2002;346:45-53.

2 American Thoracic Society/European Respiratory Society. Statement: standards for the diagnosis and management of individuals with alpha-1-antitrypsin deficiency. Am J Respir Crit Care Med 2003;168:818-900.

3 Gadek JE, Crystal RG. Experience with replacement therapy in the destructive lung disease associated with severe alpha-1-antitrypsin deficiency. Am Rev Respir Dis 1983;127:S45-6.

4 Demeo DL, Silvermann EK. Alpha-1-antitrypsin deficiency-2: Genetic aspects of alpha(1)antitrypsin deficiency: phenotypes and genetic modifiers of emphysema risk. Thorax 2004;59:259-64.

5 Wewers MD, Casolaro MA, Sellers SE, et al Replacement therapy for alpha 1-antitrypsin deficiency associated with emphysema. N Engl J Med 1987;316:1055-62.

6 Stoller JK, Aboussouan LS. Alpha-1-antitrypsin deficiency-5: Intravenous augmentation therapy: current understanding. Thorax 2004:59:708-12.

7 Soy D, de la Roza C, Lara B, et al. Alpha-1antitrypsin deficiency: optimal therapeutic regimen based on population pharmacokinetics. Thorax 2006:61:1059-64.

8 Piitulainen E, Bernspång $E$, Björkman S, et al. Tailored pharmacokinetic dosing allows selfadministration and reduces the cost of IV augmentation therapy with human $\alpha_{1}$-antitrypsin. Eur J Clin Pharmacol 2003;59:151-6. 